\title{
Особенности ультразвуковой характеристики сосудистых мальформаций головы и шеи
}

\author{
С. П. Галич, А. А. Гуч, О. А. Гиндич, Я. П. Огородник
}

Национальный институт хирургии и трансплантологии имени А. А. Шалимова НАМН Украины, г. Киев

\section{Peculiarities of ultrasonographic characteristic of vascular malformation of head and neck}

\author{
S. P. Galych, A. A. Guch, O. A. Hyndych, Ia. P. Ogorodnyk \\ Shalimov National Institute of Surgery and Transplantology, Kyiv
}

\section{Реферат}

Цель. Использование инструментальных методов исследования для проведения дифференциальной диагностики различных типов врожденных сосудистых мальформаций (ВСМ) головы и шеи.

Материалы и методы. В клинике обследованы 86 пациентов с различными типами ВСМ головы и шеи за период с 2008 по 2018 г. Всем пациентам проведены ультразвуковое исследование (УЗИ) в серошкальном режиме и цветовое дуплексное ангиосканирование (ЦДАС) для определения пиковой систолической (ПССК) и линейной (ЛСК) скорости кровотока, а также индекса циркуляторного сопротивления (RI) и индекса пульсации (PI) по основным магистральным артериям головы и шеи.

Результаты. У пациентов с артериовенозными мальформациями (АВМ) ПССК составила $(96,57 \pm 8,54)$ см/с, ЛСК $(46,33 \pm 5,59) \mathrm{cm} / \mathrm{c}$, у пациентов с капиллярными $(\mathrm{KM})$ и венозными (BM) мальформациями $-(57,53 \pm 4,63)$ и $(28,78 \pm$ $3,45)$ см/с соответственно.

Выводы. С использованием ЦДАС возможно проводить дифференциальную диагностику различных типов ВСМ.

ключевые слова: врожденная сосудистая мальформация; цветовое дуплексное ангиосканирование; пиковая систолическая скорость кровотока; индекс циркуляторного сопротивления; индекс пульсации.

\section{Abstract}

Objective. Application of instrumental methods of investigation for conduction of differential diagnosis of various types of the inborn vascular malformations (IVM) of the head and neck.

Materials and methods. In 1008-2018 yrs 86 patients, suffering various types of the head and neck IVM, were examined. In all the patients ultrasonographic investigation in a gray-scale regime and a color duplex angioscanning (CDAS) for determination of the peak systolic (PS) and linear (LS) velocity of the blood flow, as well as index of circulatory resistance (ICR) and the pulsation index (PI) along the main arteries of head and neck, were conducted.

Results. In the patients with arterio-venous malformations (AVM) the peak systolic velocity have constituted $(96.57 \pm 8.54)$ $\mathrm{cm} / \mathrm{s}$, and a linear systolic velocity $-(46.33 \pm 5.59) \mathrm{cm} / \mathrm{s}$, while in patients with capillary and venous malformations $-(57.53 \pm$ $4.63)$ and $(28.78 \pm 3.45) \mathrm{cm} / \mathrm{s}$, accordingly.

Conclusion. Using CDAS it is possible to conduct a differential diagnosis, and it is possible to conduct differential diagnosis of various types of IVM.

Keywords: inborn vascular malformation; the color duplex angioscanning; the peak systolic velocity of the blood flow; index of circulatory resistance; index of the pulse.

Подходы к диагностике и лечению ВСМ головы и шеи до настоящего времени окончательно не определены. Это объясняется большим разнообразием анатомических и гемодинамических нарушений, возникающих при данном заболевании, в связи с чем необходим индивидуальный подход в каждом конкретном наблюдении, использование различных диагностических технологий с целью определения не только структуры артериальной и венозной систем, но и функциональных изменений кровообращения.

\section{Материалы и методы исследования}

За период с 2008 по 2018 г. обследованы 86 пациентов с ВСМ головы и шеи. У 20 пациентов были ВМ, которые у 16 пациентов локализовались в области щек (9), губ (5), век (2), а у 4 пациентов отмечена обширная мальформация лица, нижней челюсти с вовлечением в процесс языка и глотки. КМ были у 31 пациента. Во всех наблюдениях в обширный патологический процесс были вовлече- ны сразу несколько эстетических единиц лица соответственно зонам иннервации ветвями тройничного нерва (щека, верхняя/нижняя губа, верхнее/нижнее веко, ухо, шея). АВМ наблюдали у 35 пациентов. У них мальформации также были обширными и затрагивали сразу несколько эстетических единиц головы и шеи.

Всем пациентам проводили УЗИ в серошкальном режиме и ЦДАС. Оценивали анатомические особенности строения артериальной и венозной систем, определяли количественные показатели - ПССК по артериям и ЛСК по венам, рассчитывали RI и PI.

У 20 (23,3\%) больных с КМ наблюдали диффузное утолщение кожи, подкожной жировой клетчатки и мягких тканей. По данным УЗИ в серошкальном режиме отмечено гиперэхогенное уплотнение кожи и мягких тканей по сравнению с контрлатеральной здоровой стороной. У 22 (25,6\%) пациентов при ЦДАС определялся симметричный кровоток без отклонений от нормы. 
Такие характеристики кровотока характерны для простых КМ. У 9 (10,5\%) больных при ЦДАС и спектральном анализе кровотока регистрировали его ускорение и снижение RI в бассейне наружной сонной артерии, что свидетельствовало о наличии артериовенозных шунтов. У 5 (5,8\%) пациентов артериовенозные фистулы не визуализировались. У 4 (4,7\%) пациентов на фоне измененных параметров кровотока в области мальформации (щека, верхняя губа) визуализировались единичные артериовенозные макрофистулы с ускоренным турбулентным кровотоком.

У всех пациентов с ВМ отсутствовали выраженные ультразвуковые гемодинамические проявления. У пациентов с мальформациями в области щеки при наличии внутримышечных «каверн» изучали локализацию, размеры полостей, их связь с венозной системой. Дополнительно изучали строение подкожной клетчатки и мышечной ткани в зонах патологических изменений сосудов. Перед выбором тактики лечения больных с ВМ важно было определить связь дисплазированных мышечных вен с магистральными сосудами. С целью повышения точности диагностики у всех больных выполняли ультразвуковую локацию с прицельной пальцевой компрессией различных зон пораженной мышцы. Усиление кровотока во время компрессии позволяло улучшить визуализацию элементов мальформации и определить пути оттока крови.

У больных с АВМ регистрировали выраженные нарушения регионарной гемодинамики. Определяли ускорение кровотока по питающей артерии до 0,8 - 1,0 м/с (по контрлатеральных сосудах - 0,3 - 0,4 м/с). Наличие артериовенозного шунтирования крови подтверждали феномен турбулентности и снижение RI. Венозный кровоток был ускорен, в допплеровском спектре регистрировали пульсовой компонент. Помимо изменений со стороны магистральных артерий и вен, визуализировали множество извитых сосудов диаметром 0,1 - 0,2 см, скорость кровотока по которым достигала 1,0 - 1,1 м/с, RI был снижен до 0,4 - 0,5. Указанные изменения регистрировали в зоне артериовенозного сброса крови. Кроме того, применяли энергетическое картирование, более чувствительное при исследовании мальформаций с замедленным кровотоком, чем цветовое, что позволяло более четко лоцировать мелкие сосуды.

\section{Результаты}

Ультразвуковая характеристика заболевания зависела от распространенности диспластических изменений сосудов. При ВМ головы и шеи отмечали следующие признаки: хаотично расположенные субфасциальные каверны диаметром до 2 см, часть которых содержала эхо-плотные включения (флеболиты); вены, спадающиеся при компрессии датчиком с усилием; снижение или отсутствие спонтанного кровотока; определение вихревых потоков крови внутри каверн при сокращении мышц или компрессии мягких тканей; уплотнение стенок вен; уменьшение толщины, нарушение структуры, резкое уплотнение мышечной ткани в зоне расположения каверн.

У всех пациентов с ВМ щек процесс был ограниченным, расширение вен регистрировали в пределах мышц, преимущественно жевательной. Определяли множество венозных каверн различной формы и размеров. В состоянии покоя кровоток в них не регистрировался. Стенки каверн были тонкими, плотными, у 4 пациентов определялись флеболиты. При наклоне головы сосуды увеличивались в диаметре, для их компрессии приходилось прикладывать усилие. Указанные факторы свидетельствовали о наличии выраженной венозной гипертензии. Соустья венозных каверн с магистралями имели небольшой диаметр, что затрудняло отток крови. Регионарные магистральные вены не изменены.

У 5 пациентов с ВМ губ изменения были представлены не кавернами, а эктазированными венозными сосудами в круговой мышце рта. Венозный отток осуществлялся в основные ветви наружной яремной вены, преимущественно в лицевую вену. Мышечная ткань в области мальформации (жевательная мышца, круговая мышца рта) была структурно изменена, истончена, резко уплотнена, замещена венозными образованиями.

У пациентов с обширными ВМ нижней трети лица, языка и глотки определяли распространенное поражение сосудов нескольких мышц, расширение регионарных магистральных вен, однако четкого отображения границ распространения и размеров получить не удалось, в связи с чем пациентам выполнили магнитно-резонансную томографию (МРТ).

Во всех наблюдениях изменений скоростных параметров и индексов спектральных характеристик артериального кровотока в зонах мальформации не выявлено, что свидетельствовало об изолированном поражении венозной системы.

Анализ полученных данных показал, что у больных с ВМ вследствие выраженного повышения давления и эктазии вен существуют высокий риск развития нарушения трофики тканей и угроза возникновения тромбообразования и кровотечения из измененных вен. При этой форме мальформации патологический процесс распространяется на мышцы и кости головы и шеи, вызывая функциональную недостаточность органов.

По результатам обследования пациентов с АВМ были выделены следующие характерные признаки заболевания: расширение магистральных артерий в зоне мальформации; ускорение кровотока, повышение амплитуды положительной диастолической фазы; снижение RI и PI, появление турбулентности в спектре кровотока; распространение указанных изменений кровотока на расстояние по магистральным артериям; расширение регионарных вен; ускорение венозного кровотока, появление пульсового компонента в спектре кровотока; резкое ускорение кровотока, турбулентность, низкие показатели RI и PI в зоне расположения шунтов; нарушение структуры мышечной ткани.

УЗИ мягких тканей и сосудов области головы и шеи позволило установить, что выраженность указанных изменений зависит прежде всего от калибра пораженных сосудов, размеров и плотности расположения артериовенозных шунтов. Были определены показатели кровотока, дающие основание для проведения дифференциальной диагностики и постановки предположительного диагноза. При ВСМ с замедленным кровотоком (КМ, ВМ) ПССК составила $(57,53 \pm 4,63)$ см/с, ЛСК - $(28,78 \pm 3,45)$ см/с, при ВСМ с ускоренным кровотоком (АВМ) - $(96,57$ $\pm 8,54)$ и $(46,33 \pm 5,59)$ см/с соответственно.

Таким образом, когда при УЗИ в серошкальном режиме наблюдали гиперэхогенное уплотнение кожи и мяг- 


\begin{tabular}{|c|c|c|c|c|c|c|c|c|c|}
\hline \multicolumn{10}{|c|}{ Показатели ПССК, RI, PI магистральных артерий головы и шеи } \\
\hline \multirow{3}{*}{ Артерия } & \multirow{2}{*}{\multicolumn{3}{|c|}{ Норма/КM/ВM }} & \multicolumn{6}{|c|}{$A B M$} \\
\hline & & & & \multicolumn{3}{|c|}{ микрофистулезная } & \multicolumn{3}{|c|}{ макрофистулезная } \\
\hline & $\Pi C C, \mathrm{~cm} / \mathrm{C}$ & RI & $\mathrm{PI}$ & $\Pi C C, \mathrm{~cm} / \mathrm{c}$ & $\mathrm{RI}$ & $\mathrm{PI}$ & $\Pi C C, \mathrm{~cm} / \mathrm{C}$ & $\mathrm{RI}$ & $\mathrm{PI}$ \\
\hline Наружная сонная & $85,88 \pm 3,13$ & $0,78 \pm 0,02$ & $2,6 \pm 0,1$ & $92 \pm 7,39$ & $0,64 \pm 0,04$ & $1,6 \pm 0,0$ & $109 \pm 5,45$ & $0,58 \pm 0,03$ & $0,8 \pm 0,0$ \\
\hline Лицевая & $43 \pm 3,54$ & $0,7 \pm 0,01$ & $2,8 \pm 0,1$ & $55,52 \pm 2,95$ & $0,57 \pm 0,03$ & $2,1 \pm 0,0$ & $116 \pm 9,33$ & $0,36 \pm 0,06$ & $1,0 \pm 0,0$ \\
\hline $\begin{array}{l}\text { Поверхностная } \\
\text { височная, } \\
\text { верхнечелюстная, } \\
\text { затылочная }\end{array}$ & $35,18 \pm 3,74$ & $0,67 \pm 0,03$ & $2,8 \pm 0,0$ & $45,86 \pm 2,42$ & $0,56 \pm 0,04$ & $1,9 \pm 0,1$ & $113 \pm 10,58$ & $0,28 \pm 0,02$ & $1,0 \pm 0,0$ \\
\hline
\end{tabular}

ких тканей по сравнению с контрлатеральной стороной, а по результатам ЦДАС отмечали симметричный кровоток без отклонений от нормы (ПССК артериального кровотока и ЛСК венозного кровотока в пределах указанных показателей), констатировали простую КМ или ВМ. Ускорение кровотока свидетельствовало о наличии артериовенозных шунтов. При обширных и диффузных АВМ метод был недостаточно информативен для четкой визуализации распространения обширных поражений у 12 (14\%) пациентов и определения внутрикостного компонента ВСМ у 4 (4,7\%) пациентов, в связи с чем для уточнения диагноза им выполнили МРТ и компьютерную томографию (КТ)-ангиографию. В результате выполнения ультразвуковых дуплексных исследований различных типов мальформаций головы и шеи определили показатели ПССК, RI, PI артерий в норме и при патологии, на основании которых проводили дифференциальную диагностику заболевания (см. мабличу).

Таким образом, повышение скорости кровотока, а также снижение RI на величину 0,1-0,2 и PI на величину 0,5 - 1,0 в сравнении с симметричным здоровым сегментом свидетельствовало о снижении периферического сосудистого сопротивления вследствие артериовенозного сброса.

Анализ полученных результатов показал, что при АВМ развивается тяжелое нарушение регионарной гемодинамики, угрожающее возникновением кровотечения, нарушений трофики тканей с грубой деформацией лица и шеи, разрушениями костной ткани.

\section{Обсуждение}

Начальным этапом в алгоритме инструментальной диагностики ВСМ является ЦДАС, позволяющее установить наличие и распространенность мальформаций, определить анатомические особенности изменений сосудов и скорость кровотока в них [1]. Н. P. Zwеер и соавторы продемонстрировали, что на основании тщательно изученных клинических тестов, анамнестических данных и применения УЗИ может быть достаточно четко поставлен диагноз и разработана лечебная тактика, а в процессе лечения, по данным I. Trop и соавторов, метод имеет большое значение для контроля изменения кровотока в зоне вмешательства [2, 3].

В нашем исследовании применение УЗИ во всех наблюдениях позволило определить ориентировочные границы и размеры образования, а также дифференцировать сосуды с высокоскоростными и низкоскоростными допплеровскими характеристиками, что соответствует данным В. Mahesh и соавторов [4].
Однако у пациентов с обширными ВМ и АВМ метод был недостаточно информативен для четкого отображения распространения обширных поражений и визуализации внутрикостного компонента сосудистой мальформации, в связи с чем для уточнения диагноза им выполнили МРТ и КТ-ангиографию. На аналогичный недостаток УЗИ указывали S. Hovius и соавторы, L. Fordham и соавторы $[5,6]$. По данным Leng Tingting ЦДАС недостаточно эффективно для определения источника ВСМ, точной связи между сосудистой мальформацией и окружающими структурами, что особенно важно при локализации заболевания в области лица и шеи [1]. O. Enjolras и соавторы считают, что при диагностике распространенных ВМ более информативны КТ и МРТ. При таком типе ВСМ авторы наблюдали поражение мышц у 100\%, костей - у 63\% пациентов [7]. Тем не менее, метод ЦДАС позволяет достоверно установить форму и локализацию сосудистых нарушений, определить количественные показатели регионарной гемодинамики, оценить степень нарушения артериального и венозного кровотока. Полученные результаты помогают установить предварительный диагноз и определить тактику дальнейших исследований.

\section{References}

1. Leng Tingting, Wang MM Ximing, Huo Ran, Cheng Zhaoping, Feng Yongqiang. The value of three-dimensional computed tomographic angiography in the diagnosis and treatment of vascular lesions. Plast Reconstr Surg. 2008 Nov;122:1417-24. doi: 10.1097/PRS.0b013e318188210d.

2. Zweep HP, Rieu PN, van Die CE, Boll AP, Steijlen PM, Spauwen PH. Haemangiomas and congenital vascular malformations: their classification and diagnosis. Ned Tijdschr Geneeskd. 2002;146(23):1072-7. PMID: 12085555.

3. Trop I, Dubois J, Guibaud L, Grignon A, Patriquin H, McCuaig C, et al. Soft-tissue venous malformations in pediatric and young adult patients: diagnosis with Doppler US. Radiology. 1999;212:841-5. doi: 10.1148/ radiology.212.3.r99au11841.

4. Mahesh B, Thulkar S, Joseph G, Khazanchi RK, Srivastava A. Colour duplex ultrasound-guided sclerotherapy: a new approach to the management of patients with peripheral vascular malformations. Clin Imaging. 2003;27(3):171-9. doi: 10.1016/S0899-7071(02)00503-X.

5. Hovius SER, Borg DH, Paans PR, Pieterman H. The diagnostic value of magnetic resonance imaging in combination with angiography in patients with vascular malformations: a prospective study. Ann Plast Surg. 1996;37:278-85. PMID: 8883726.

6. Fordham LA, Chung CJ, Donnelly LF. Imaging of congenitalvascular and lymphatic anomalies of the head and neck. Neuroimaging Clin $\mathrm{N}$ Am. 2000;10:117-36. doi: 10.5152/dir.2014.14004.

7. Enjolras O, Ciabrini D, Mazoyer E, Laurian C, Herbreteau D. Extensive pure venous malformations in the upper or lower limb: a review of 27 cases. J Am Acad Dermatol.1997;36 (2 Pt 1):219-25. PMID: 9039172. 